\title{
Discovery of Novel Dot1L Inhibitors through a Structure-Based Fragmentation Approach
}

Chao Chen, ${ }^{\dagger}$ Hugh Zhu, ${ }^{\dagger}$ Frédéric Stauffer, ${ }^{\ddagger}$ Giorgio Caravatti, ${ }^{\ddagger}$ Susanne Vollmer, ${ }^{\ddagger}$ Rainer Machauer, Philipp Holzer, ${ }^{\star}$ Henrik Möbitz, ${ }^{\ddagger}$ Clemens Scheufler, Martin Klumpp, ${ }^{\ddagger}$ Ralph Tiedt, ${ }^{\ddagger}$ Kim S. Beyer,

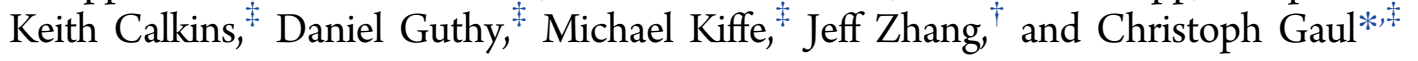

${ }^{\ddagger}$ Novartis Institutes for Biomedical Research, 4002 Basel, Switzerland

${ }^{\dagger}$ Novartis Institutes for Biomedical Research, Shanghai 201203, China

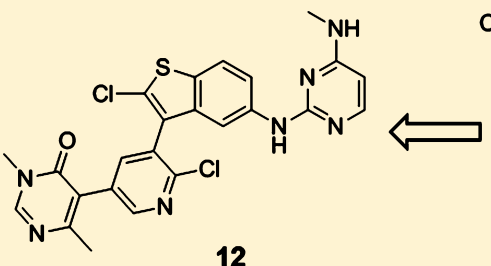

12

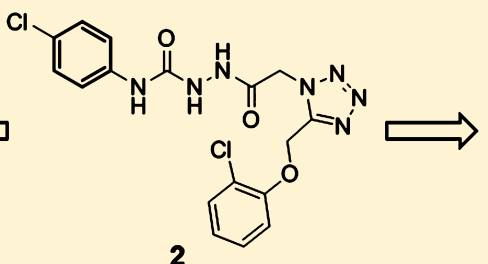

2

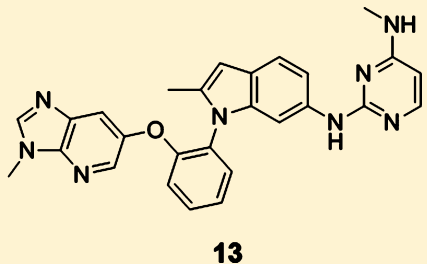

13

ABSTRACT: Oncogenic MLL fusion proteins aberrantly recruit Dot1L, a histone methyltransferase, to ectopic loci, leading to local hypermethylation of $\mathrm{H} 3 \mathrm{~K} 79$ and misexpression of HoxA genes driving MLL-rearranged leukemias. Inhibition of the methyltransferase activity of Dot1L in this setting is predicted to reverse aberrant H3K79 methylation, leading to repression of leukemogenic genes and tumor growth inhibition. In the context of our Dot1L drug discovery program, high-throughput screening led to the identification of 2 , a weak Dot1L inhibitor with an unprecedented, induced pocket binding mode. A medicinal chemistry campaign, strongly guided by structure-based consideration and ligand-based morphing, enabled the discovery of 12 and 13, potent, selective, and structurally completely novel Dot1L inhibitors.

KEYWORDS: Dot1L, protein lysine methyltransferase, inhibitor, mixed lineage leukemia, protein structure-based design

$\mathrm{P}$ rotein lysine methyltransferases (PKMT) are a class of 51 enzymes that catalyze the transfer of a methyl group from cofactor $S$-adenosylmethionine $(S A M)$ to the lysine $\varepsilon$-amino group of proteins. $^{1-3}$ Typically, PKMTs mono-, di-, or trimethylate lysine residues of histone proteins, thereby controlling chromatin structure and transcriptional accessibility of genes. However, a number of other nonhistone substrate proteins have also been identified. ${ }^{4}$

Dot $1 \mathrm{~L}$ is a $165 \mathrm{kD}$ a protein comprising 1537 amino acids. The catalytic domain of Dot $1 \mathrm{~L}$, residing in the $N$-terminal 400 amino acids, is structurally distinct to the SET-domain containing protein lysine methyltransferases and clusters more closely with the catalytic domain of a related class of proteins, the protein arginine methyltransferases (PRMT).,5 Dot1L is the only known enzyme to methylate lysine 79 of histone 3 (H3K79), with the H3K79me2 mark being associated with active transcription. $^{6-8}$ Under physiological conditions, Dot $1 \mathrm{~L}$ is critical for normal hematopoiesis; ${ }^{9,10}$ however, misdirected catalytic activity is believed to be causative for a subset of acute leukemias. ${ }^{11,12}$ Several oncogenic fusion proteins including MLL-ENL, MLL-AF4, and MLL-AF9 aberrantly recruit Dot1L to ectopic loci, leading to local hypermethylation of H3K79 and misexpression of genes (including HoxA), which drive the leukemic phenotype. Inhibition of the methyltransferase activity of Dot1L in MLL-rearranged leukemias (mixed lineage leukemia, MLL) is predicted to reverse ectopic H3K79 methylation, leading to repression of leukemogenic genes (HoxA9, Meis1) and tumor growth inhibition. ${ }^{13}$ The recent quest for Dot1L inhibitors has been spearheaded by Epizyme and culminated in the discovery of EPZ-5676, a SAM-competitive, nucleosidecontaining Dot1L inhibitor, which is currently being evaluated in MLL patients in Phase $1 \mathrm{~b}$ clinical trials. ${ }^{14}$ The agent is administered by uninterrupted, continuous intravenous (i.v.) infusion due to its physicochemical properties. ${ }^{15}$ Other research groups, based at Baylor College and the Structural Genomics Consortium, have identified additional Dot1L inhibitors structurally related to EPZ-5676. ${ }^{16-19}$

Herein, we describe the discovery of SAM-competitive, structurally novel Dot1L inhibitors, which bind to an induced pocket adjacent to the SAM binding site. The compounds display cellular potency and molecular properties suitable for further optimization.

A variety of approaches to discover chemical starting points in the Dot $1 \mathrm{~L}$ program were taken and included virtual, biophysical, and biochemical screens. In our high-throughput screening (HTS) campaign, a luminescence-based coupled assay ${ }^{20}$ was used to measure Dot1L-catalyzed nucleosome methylation and miniaturized to allow screening of the Novartis Compound

Received: April 21, 2016

Accepted: June 1, 2016

Published: June 1, 2016 
Collection in 1536-well plates (primary hit rate $0.47 \%$, threshold $50 \%$ inhibition at $26.7 \mu \mathrm{M}$ compound concentration). For $\mathrm{IC}_{50}$ and $K_{\mathrm{i}}$ determinations, a scintillation proximity assay (SPA) format was employed as a more direct readout, quantifying enzyme activity via the amount of the transfer of ${ }^{3} \mathrm{H}$-labeled methyl group from SAM to biotinylated nucleosomes. Experiments described herein were carried out at SAM concentration equal to $K_{\mathrm{M}}$, while nucleosome concentration was in excess relative to $K_{\mathrm{M}}$ (Supporting Information). In the HTS, a commercial compound sample, assigned to structure 1 , was identified as an inhibitor of Dot1L $\left(\mathrm{IC}_{50}=14 \mu \mathrm{M}\right)$ (Figure 1).
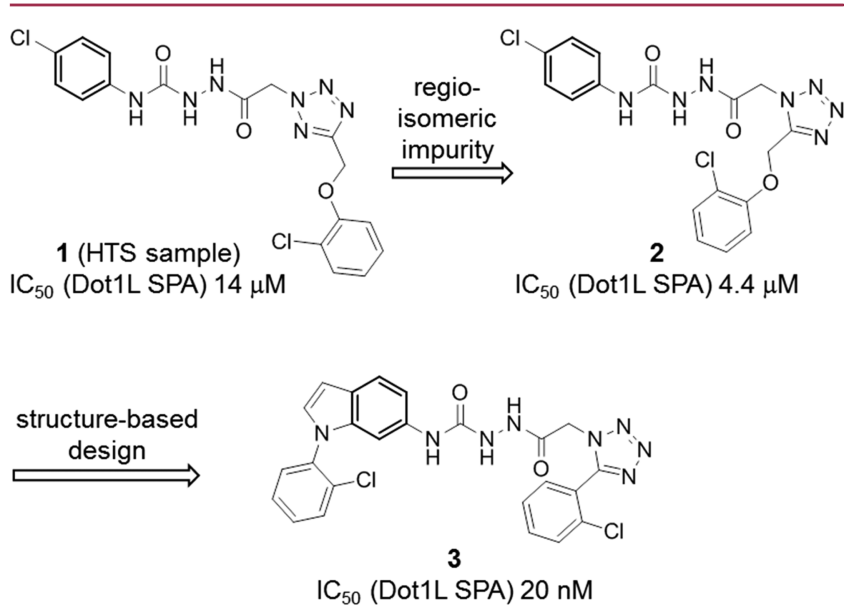

Figure 1. Protein structure-guided optimization of HTS hit 1.

Analysis of the screening sample revealed that the active principle is a regioisomeric impurity, compound $2\left(\mathrm{IC}_{50}=4.4 \mu \mathrm{M}\right)$, whereas purified 1 had no inhibitory activity up to $100 \mu \mathrm{M}$.

The crystal complex structure with compound 2 was solved using the catalytic domain of Dot1L (Figure 2, PDB code 5drt). To our surprise, 2 binds to a newly formed pocket adjacent to the SAM binding site, inducing a fundamentally different conformation of Dot1L compared to the conformation of SAMbound Dot $1 \mathrm{~L}$ (Figure 2B). ${ }^{21}$ A flexible loop comprising amino acids 126-140, which forms the "lid" of the SAM binding pocket in the SAM-bound state, is completely rearranged and partially disordered and forms a part of the induced binding pocket of 2 . We and others subsequently observed that only SAM and SAH are able to induce a closed lid (e.g., PDB code 3uwp), whereas inhibitors rearrange and often engage the flexible loop. ${ }^{16,22}$ Other residues, such as Leu143, Met147, Phe239, and Tyr312, also undergo conformational shifts compared to the SAM-bound complex and are forming the bottom lining of the binding pocket of $\mathbf{2}$. Remarkably, $\mathbf{2}$ forms five direct hydrogen bonds with Dot $1 \mathrm{~L}$ (Figure 2A). The central urea NHs are coordinating Asp161, whose side chain rotation is cushioned by crystal waters. The interaction of the urea carbonyl with Asn241 varies between 3.2 and $3.8 \AA$ across several cogeneric cocrystal structures. The urea of 2 interacts with Dot1L in a comparable fashion to the ureacontaining Dot1L inhibitor EPZ-4777. ${ }^{16}$ The second hydrazide amide forms a hydrogen bond to Gly163 perpendicular to the urea plane and stacks onto the Ser164-Gly165 backbone amide. The tetrazole forms a hydrogen bond with Gln168, and the tetrazole-phenoxy motif engages the flexible loop through hydrophobic contacts, while the $p$-chlorophenyl substituent slides between the Asn241-containing loop and an $\alpha$-helix, occupying a similar position as the tert-Bu group of EPZ-5676 (Figure 2C).

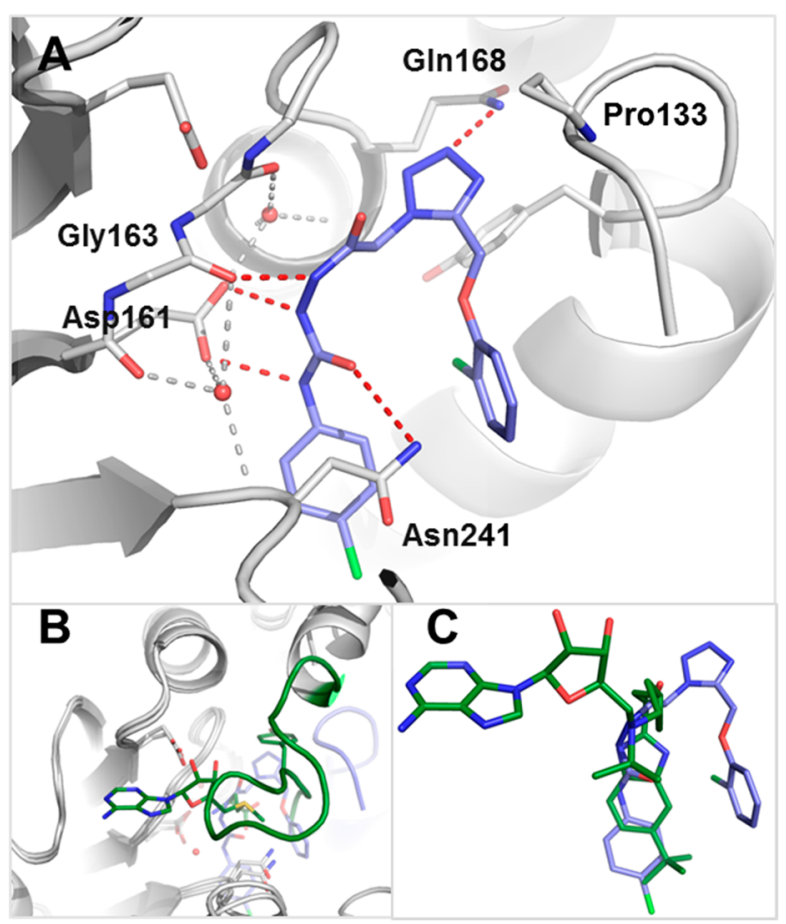

Figure 2. (A) X-ray cocrystal structure of Dot1L (gray) with 2 (blue) (PDB code 5drt). Amino acid side chains engaged in key interactions with the ligand are illustrated as sticks. Key polar interactions of Dot $1 \mathrm{~L}$ and $\mathbf{2}$ are shown as red dotted red lines, the tetrahedral coordination of the two waters ligating Asp161 as gray dotted lines. (B) Comparison of the flexible loop (amino acids 126-140) in Dot1L bound to 2 (blue, protein gray) (PDB code 5drt) and SAM (green) (PDB code 3qow). (C) Overlay of ligands 2 (blue) (PDB code 5drt) and EPZ-5676 (green) (PDB code $4 \mathrm{hra}$ ) bound to Dot1L in the same view as $2 \mathrm{~A}$. PyMol was used for structural visualization and figure preparation. ${ }^{25}$

Structural analysis of the Dot1L-compound $\mathbf{2}$ complex revealed a large hydrophobic pocket, which is only partially filled by the $p$-chlorophenyl substituent. Structure-based chemistry optimization led to the discovery of the significantly more potent compound $3\left(\mathrm{IC}_{50}=20 \mathrm{nM}\right)$ in which the $p$ chlorophenyl substituent was replaced by an $N$-arylated indole system (Figure 1). The indole core is deeply buried in a hydrophobic cleft, while the $N$-phenyl moiety engages in a faceedge interaction with Phe131 thereby further stabilizing the flexible loop of Dot1L (Figure 3, PDB code 5dry). The $o-\mathrm{Cl}$ substituent does not only preorganize the bioactive conformation of 3 but also fills a hydrophobic nook of Dot1L.

Inhibitor 3 shows low permeability as assessed in the parallel artificial membrane permeation (PAMPA) assay, which might not be surprising, considering its number of hydrogen bond acceptors and donors (Supporting Information). It is likely that the weak flux of 3 contributes to the lack of oral bioavailability in rats and weak cellular activity.

Considering the poor physicochemical properties, the complex functional group arrangement, and high molecular weight $(\mathrm{MW}=521)$, we regarded 3 unsuitable for further stepwise optimization. Therefore, we decided to pursue a more radical fragmentation approach in which the entire aryl-tetrazole system was eliminated leading to urea 4 , which showed residual biochemical potency $\left(\mathrm{IC}_{50}=40 \mu \mathrm{M}\right)$ (Figure 4$)$. Compound 4 was viewed as a more suitable starting point for additional chemistry activities. Initial work focused on the identification of urea replacements with the goal to reduce the risk of low 


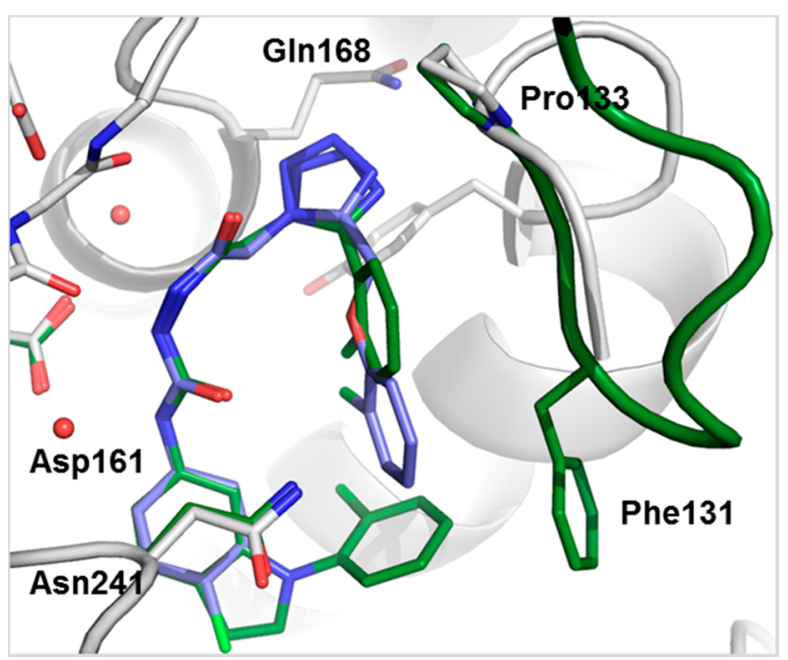

Figure 3. Overlay of X-ray cocrystal structures of Dot1L with 2 (ligand blue, protein gray) (PDB code 5drt) and 3 (ligand green, parts of the protein green) (PDB code 5dry). Prominent amino acid side chains are illustrated as sticks.

solubility and poor permeability often associated with ureas. A series of functional groups were discovered as urea isosteres capable of coordinating the central Asp161 side chain of Dot1L. Diamino-pyrimidines 5 and 6 (in their protonated forms), amino-pyrimidone 7 , amino-pyridazine 8 (with its polarized C$\mathrm{H}$ group), and amino-imidazolone 9 inhibit Dot1L with improved potency compared to urea 4 (Figure 4). It is worth noting that the methyl group in the 2-position of the indole and the insertion of a nitrogen atom into the $\mathrm{N}$-phenyl substituent typically contribute to the potency by a 5 -fold reduction of the $\mathrm{IC}_{50}$. Remarkably, the $\mathrm{N}$-methyl group of 6 increases inhibitory activity against Dot $1 \mathrm{~L}$ by almost 20 -fold over 5 , possibly through a preorganization effect (discussed below).

The optimization opportunities for urea replacements 6 and 7 were evaluated in detail. In line with our structural understanding, the diamino-pyrimidine of 6 and the aminopyrimidone of 7 undergo polar interactions with Asp161 (Figure $5)$. The $N$-aryl 2-methylindole core of both analogues is shapecomplementary to the hydrophobic pocket formed by the Asn241-containing loop and the $\alpha$-helix. Importantly, the carbonyl group of amino-pyrimidone 7 and the $N$-methyl group of diamino-pyrimidine 6 interact with Dot1L in distinct

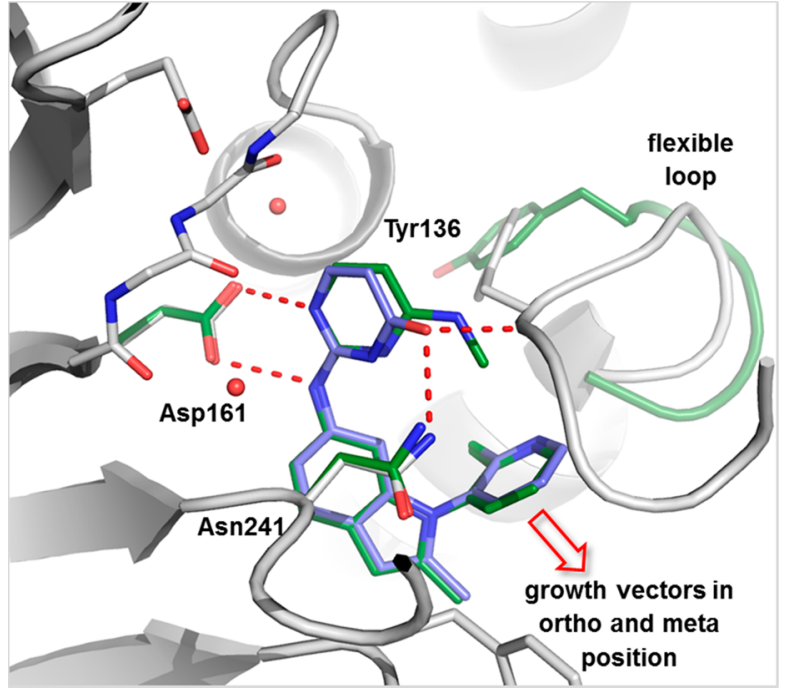

Figure 5. Overlay of X-ray cocrystal structures of Dot1L with 6 (ligand green, parts of the protein green) and 7 (ligand blue, protein gray). ${ }^{23}$ Amino acid side chains engaging in key interactions with the ligands are illustrated as sticks; polar contacts are highlighted as dotted red lines. Growth vectors (solid red arrow) open in ortho- and meta-positions for 6, but blocked for 7 due to tighter engagement of the flexible loop.

ways: The $N$-methyl group of 6 does not undergo any specific contacts with Dot $1 \mathrm{~L}$, but rather plays a role in preorganizing the ligand by pointing into the $N$-aryl moiety (van der Waals contact). In contrast, the carbonyl group of 7 engages in polar interactions with Asn241 and the backbone NH of Tyr136, thereby tightly stabilizing the flexible loop of Dot1L (Figure 5). Consequently, potential growth vectors in ortho- and metaposition of the $N$-pyridyl moiety of pyrimidone 7 are blocked by the loop, whereas they are open for pyrimidine 6 (Figure 5).

Both growth vectors, extruding from either the ortho- or the meta-position, were explored for $\mathbf{6}$. Guided by above-mentioned protein-structural considerations, the direct attachment of a pyridone in meta-position, leading to compound 10 (Figure 6), turned out to have a beneficial impact on potency $\left(\mathrm{IC}_{50}=10\right.$ $\mathrm{nM})$. Growing 6 from the ortho-position was best achieved with an aryloxy group while eliminating the $\mathrm{Cl}$ substituent in the "other" ortho-position, as, e.g., in compound $11\left(\mathrm{IC}_{50}=150 \mathrm{nM}\right)$ (Figure 6).
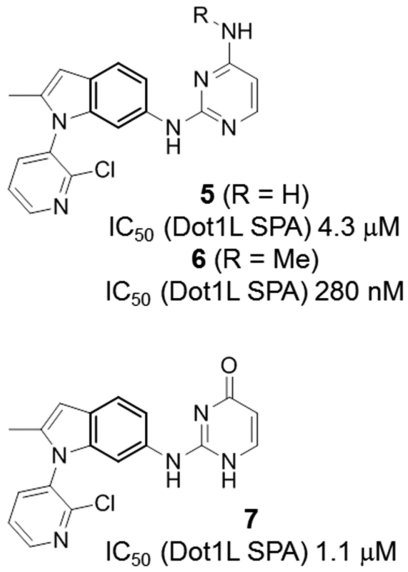

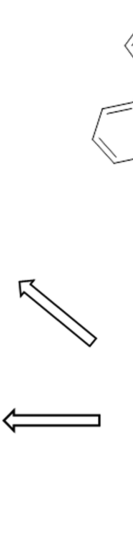

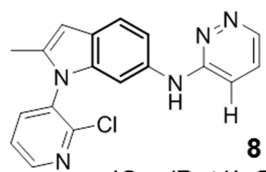

$\mathrm{IC}_{50}$ (Dot1L SPA) $28 \mu \mathrm{M}$
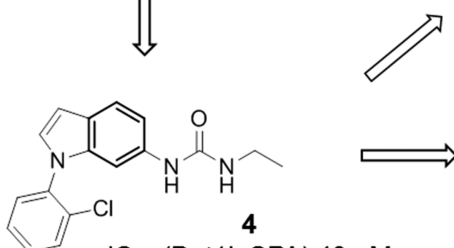

$\mathrm{IC}_{50}$ (Dot1L SPA) $40 \mu \mathrm{M}$

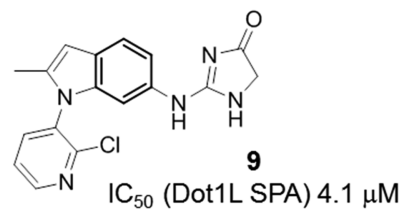

Figure 4. Fragmentation of 3 to urea 4. Discovery of urea replacements 5-9. 


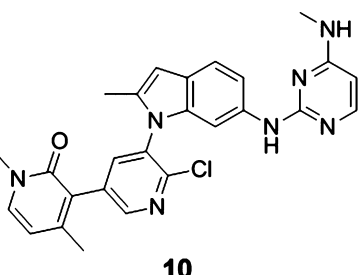

$\mathrm{IC}_{50}$ (Dot1L SPA) $10 \mathrm{nM}$

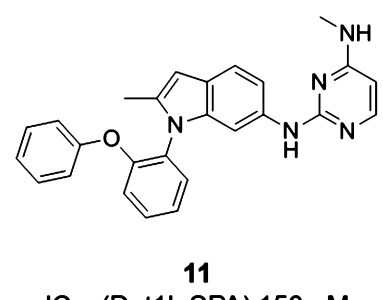

$\mathrm{IC}_{50}$ (Dot1L SPA) $150 \mathrm{nM}$

Figure 6. Optimization of 6 by growing from the meta-position, leading to 10 , or from the ortho-position, leading to $\mathbf{1 1}$.

Analysis of the X-ray cocrystal structures of 10 and 11 bound to Dot1L revealed some noteworthy aspects (Figure 7, PDB

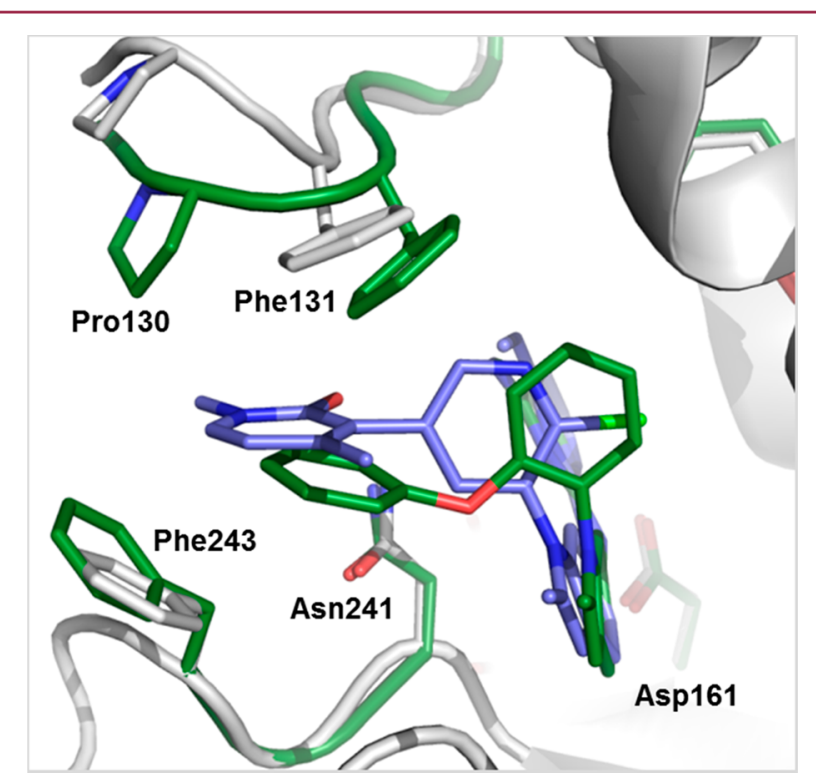

Figure 7. Overlay of ligands 10 (ligand blue, protein gray) (PDB code $5 \mathrm{dsx}$ ) and 11 (ligand green, parts of the protein green) (PDB code 5dt2) bound to Dot1L based on X-ray cocrystal structures. Both aromatic extensions engage Phe243 and the Pro130-Phe131 motif of the flexible loop.

codes $5 \mathrm{dsx}$ and $5 \mathrm{dt} 2$ ): both compounds stack tightly with Phe243 and engage the flexible loop through their diaryl and diaryl ether groups, respectively. Furthermore, the pyridone carbonyl of $\mathbf{1 0}$ forms a hydrogen bond to the side-chain $\mathrm{NH}_{2}$ of Asn241. The $N$-phenyl group of $\mathbf{1 1}$ moves deep into the hydrophobic pocket, taking the place of the $o$-Cl substituent of 10.

Chemistry optimization continued on both structural subtypes exemplified by compounds 10 ("meta") and $\mathbf{1 1}$ ("ortho"). A number of opportunities were discovered to further improve potency. For example, the 2-methylindole core of $\mathbf{1 0}$ can be replaced by a 2-chloro benzothiophene core, leading to the highly potent Dot1L inhibitor $12\left(\mathrm{IC}_{50}=1.4 \mathrm{nM}\right)$ (Table 1$)$. Along different lines, the aromatic stacking capacity of 11 can be dramatically improved by substituting the outer phenyl group of 11 by an aza-benzimidazole group, resulting in 400 -fold more potent compound $13\left(\mathrm{IC}_{50}=0.4 \mathrm{nM}\right)$. Both compounds 12 and 13 are characterized by long on-target residence times as assessed by surface plasmon resonance experiments $(\tau=43 \mathrm{~min}$ for 12 and $>240 \mathrm{~min}$ for 13 (the detection limit of our internal SPR assay). Most importantly, $\mathbf{1 2}$ and $\mathbf{1 3}$ potently suppress H3K79 dimethylation $\left(\mathrm{IC}_{50}=23\right.$ and $16 \mathrm{nM}$, respectively), the direct

Table 1. Biochemical, Biophysical, and Cellular Characterization of Lead Compounds 12 and $13^{a}$

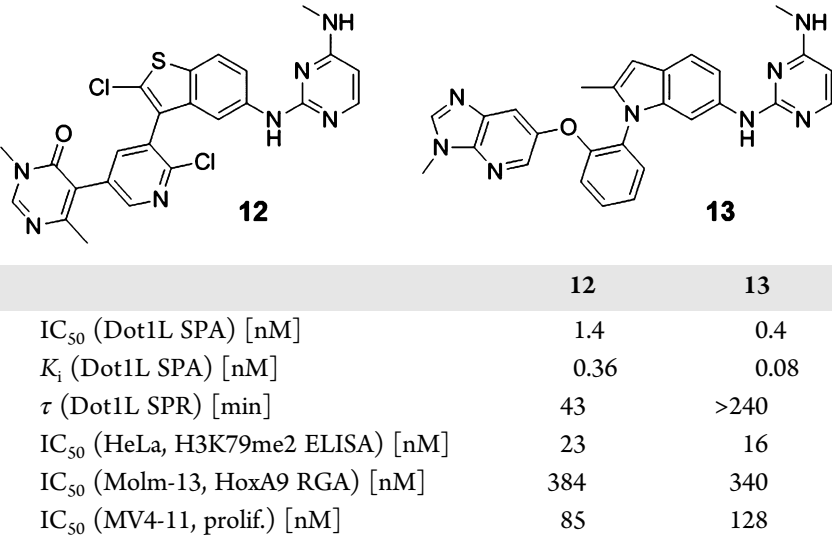

${ }^{a}$ All data are the results of at least two assay runs with the mean value reported. The coefficient of variation was less than $60 \%$ in all cases. Biochemical $\mathrm{IC}_{50}$ values were determined at $K_{\mathrm{M}}$ for SAM. $K_{\mathrm{i}}$ values were determined by applying the Morrison tight binding model (Supporting Information).

product of the Dot1L-catalyzed reaction, as well as the activity of the HoxA9 promoter ( $\mathrm{IC}_{50}=384$ and $340 \mathrm{nM}$, respectively) in cellular systems (Table 1 ). We speculate that the significantly higher SAM concentration in cells $(\sim 200 \mu \mathrm{M})^{24}$ compared to our biochemical assay $(200 \mathrm{nM})$ is contributing to the considerable cell-enzyme $\mathrm{IC}_{50}$ shift. Finally, both compounds effectively inhibit proliferation of the human MLL-rearranged leukemia cell line MV4-11 carrying the oncogenic MLL-AF4 fusion $\left(\mathrm{IC}_{50}=85\right.$ and $128 \mathrm{nM}$, respectively) (Table 1 ). Importantly, 12 and $\mathbf{1 3}$ display a favorable selectivity profile against a panel of 22 PKMTs and PRMTs with no inhibitory activity up to $50 \mu \mathrm{M}$.

By virtue of its in vitro potency and selectivity as well as good molecular properties (e.g., improved permeability vs 3, Supporting Information), 12 was evaluated in PK experiments in rats (Table 2). After intravenous bolus administration ( $1 \mathrm{mg} /$

Table 2. Pharmacokinetic Parameters of 12 in Male Sprague Dawley Rats Following IV and PO Dosing

$\begin{array}{lcc} & 1 \mathrm{mg} / \mathrm{kg} \mathrm{iv}^{a} & 15 \mathrm{mg} / \mathrm{kg} \mathrm{po}^{b} \\ \mathrm{Cl}[\mathrm{mL} / \mathrm{min} / \mathrm{kg}] & 84 & \mathrm{NA} \\ V_{\mathrm{d}}[\mathrm{L} / \mathrm{kg}] & 10 & \mathrm{NA} \\ t_{1 / 2}[\mathrm{~h}] & 1.7 & \mathrm{NA} \\ \mathrm{AUC}_{0 \text {-inf }}[\mathrm{nM} \cdot \mathrm{h}] & 396 & 2370 \\ C_{\max }[\mathrm{nM}] & \mathrm{NA} & 225 \\ \mathrm{BAV}[\%] & \mathrm{NA} & 40 \\ { }^{a} \mathrm{NMP} / \mathrm{PEG} 200(30: 70) .{ }^{b} \mathrm{MEPC} 5 / \text { Water }(10: 90) . & \end{array}$

$\mathrm{kg}$ ), the compound showed high total blood clearance, high volume of distribution, and a moderate half-life. After oral administration in suspension $(15 \mathrm{mg} / \mathrm{kg})$, blood levels were detected up to $24 \mathrm{~h}$. The maximum total concentration $(225 \mathrm{nM})$ was reached after $3.5 \mathrm{~h}$; total exposure was $2370 \mathrm{nM} \cdot \mathrm{h}$. Oral bioavailability at $15 \mathrm{mg} / \mathrm{kg}$ was $40 \%$.

Compound 12 can be conveniently prepared from commercially available 5-nitrobenzo[ $b]$ thiophene-2-carboxylic acid $\mathbf{1 4}$ (Scheme 1). Thermal decarboxylation, followed by bromination and a lithiation-chlorination sequence, yielded intermediate $\mathbf{1 5}$. Nitro reduction to $\mathbf{1 6}$ and nucleophilic aromatic substitution with chloro-pyrimidine $\mathbf{2 4}$ delivered key intermediate 17, 
Scheme 1. Synthetic Route to Compound $12^{a}$

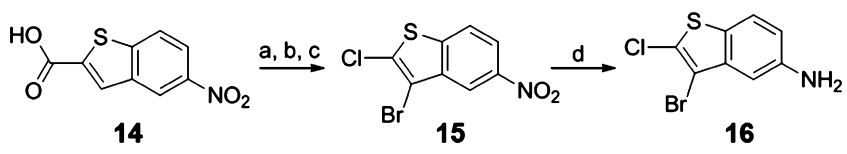<smiles>CNc1ccnc(Nc2ccc3sc(Cl)c(-c4cc(-c5c(C)ncn(C)c5=O)cnc4Cl)c3c2)n1</smiles><smiles>Cc1ncn(C)c(=O)c1-c1cnc(Cl)c(N)c1</smiles>

18 19 20<smiles>CC(C)CC(C)(C)C1(C)OB(c2cnc(Cl)c(N)c2)OC1(C)C</smiles>

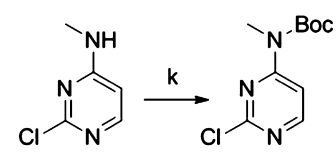

21

${ }^{a}$ Reagents and conditions: (a) $\mathrm{Cu}$, quinoline, $2 \mathrm{~h}, 150{ }^{\circ} \mathrm{C}, 81 \%$; (b) $\mathrm{Br}_{2}, \mathrm{CHCl}_{3}, 30 \mathrm{~h}, 60{ }^{\circ} \mathrm{C}, 93 \%$; (c) NCS, TMPMgCl.LiCl, THF, toluene, $-75{ }^{\circ} \mathrm{C}, 80 \%$; (d) $\mathrm{RaNi}, \mathrm{H}_{2}, \mathrm{EtOH}, \mathrm{rt}, 96 \%$; (e) 24, $p$-Ts $\mathrm{OH}$. $\mathrm{H}_{2} \mathrm{O}, \mathrm{DMF}, 15 \mathrm{~h}, 80{ }^{\circ} \mathrm{C}, 66 \%$; (f) 20, $\mathrm{Na}_{2} \mathrm{CO}_{3} 2 \mathrm{M}$ aq, $\mathrm{Pd}$ (amphos) $\mathrm{Cl}_{2}, \mathrm{MeCN}, 30 \mathrm{~min}, 80{ }^{\circ} \mathrm{C}, 25 \%$; (g) 22, $\mathrm{Na}_{2} \mathrm{CO}_{3} 2 \mathrm{M}$ aq, $\mathrm{PdCl}_{2}$ (dppf).DCM, DME, $80{ }^{\circ} \mathrm{C}$, 68\%; (h) $\mathrm{NaNO}_{2}$, KI, $\mathrm{HCl} 4 \mathrm{M}$, $\mathrm{H}_{2} \mathrm{O}, \mathrm{MeCN}, 5{ }^{\circ} \mathrm{C}$ to rt, 36\%; (i) Bis(pinacolato)diboron, KOAc, $\mathrm{PdCl}_{2}$ (dppf).DCM, dioxane, $10 \mathrm{~h}, 110^{\circ} \mathrm{C}, 49 \%$; (j) Bis(pinacolato)diboron, $\mathrm{KOAc}, \mathrm{PdCl}_{2}(\mathrm{dppf}) \cdot \mathrm{DCM}$, dioxane, $3 \mathrm{~h}, 100{ }^{\circ} \mathrm{C}, 80 \%$; (k) $\mathrm{Boc}_{2} \mathrm{O}, \mathrm{DMAP}, \mathrm{DCM}, \mathrm{rt}, 98 \%$.

suitable for late state derivatization in the 3-position of the benzothiophene core. Suzuki coupling of $\mathbf{1 7}$ with the customized boronic ester 20 produced lead compound $\mathbf{1 2}$ in a convergent fashion (Scheme 1).

In conclusion, we have discovered potent, selective, and orally bioavailable Dot1L inhibitors that have a novel binding mode and are structurally unique. Future work on further improving potency and in vivo exposure based on lead compounds 12 and 13 is warranted.

\section{ASSOCIATED CONTENT}

\section{S Supporting Information}

The Supporting Information is available free of charge on the ACS Publications website at DOI: 10.1021/acsmedchemlett.6b00167.

Synthetic procedures, compound characterization, and assay protocols (PDF)

\section{AUTHOR INFORMATION}

\section{Corresponding Author}

*E-mail: christoph.gaul@novartis.com.

\section{Author Contributions}

The manuscript was written through contributions of all authors. All authors have given approval to the final version of the manuscript.

\section{Notes}

The authors declare the following competing financial interest(s): Authors are shareholders of Novartis and/or employees of Novartis.

\section{ACKNOWLEDGMENTS}

We are grateful to our medicinal chemistry colleagues Ross Strang, Christian Ragot, Rainer Tschan, Michael Hediger, and Stephan Kläusler for their scientific contributions. We thank Kim Twesten and Anton Kessler for developing and running the highthroughput screening assay, and acknowledge supply of Dot $1 \mathrm{~L}$ enzyme and nucleosome substrate by the laboratories of Lukas Leder, Dirk Erdmann, and Kehao Zhao, respectively. Jidong Zhu is thanked for valuable and inspiring discussions on target biology, Steffen Renner for in silico hit list analysis, and Justin Gu for verification of screening hits in an orthogonal LC-MS assay. We thank Paul Westwood, Kerstin Pollehn, Shin Numao, Claudio Thoma, and Andreas Theuer for developing and supporting project-related biophysical, biochemical, and cellular assays. The authors would like to acknowledge Elke Koch, Céline Be, Aurelie Winterhalter, Aude Izaac, Julia Klopp, and Patrick Graff for their contributions to the protein structural work. The crystallographic experiments were performed on the X10SA beamline at the Swiss Light Source, Paul Scherrer Institut, Villigen, Switzerland, supported by the team of Expose GmbH. We thank Sandrine Desrayaud and her team for performing the rat PK studies as well as Bernard Faller and his team for contributing to the in vitro ADME studies.

\section{REFERENCES}

(1) Copeland, R. A.; Solomon, M. E.; Richon, V. M. Protein Methyltransferases as a Target Class for Drug Discovery. Nat. Rev. Drug Discovery 2009, 8, 724-732.

(2) Copeland, R. A. Molecular Pathways: Protein Methyltransferases in Cancer. Clin. Cancer Res. 2013, 19, 6344-6350.

(3) Richon, V. M.; Johnston, D.; Sneeringer, C. J.; Jin, L.; Majer, C. R.; Elliston, K.; Jerva, L. F.; Scott, M. P.; Copeland, R. A. Chemogenetic Analysis of Human Protein Methyltransferases. Chem. Biol. Drug Des. 2011, 78, 199-210.

(4) Hamamoto, R.; Saloura, V.; Nakamura, Y. Critical Roles of NonHistone Protein Lysine Methylation in Human Tumorigenesis. Nat. Rev. Cancer 2015, 15, 110-124.

(5) Min, J.; Feng, Q.; Li, Z.; Zhang, Y.; Xu, R.-M. Structure of the Catalytic Domain of Human Dot1L, a Non-SET Domain Nucleosomal Histone Methyltransferase. Cell 2003, 112, 711-723.

(6) Nguyen, A. T.; Zhang, Y. The Diverse Functions of Dot1 and H3K79 Methylation. Genes Dev. 2011, 25, 1345-1358.

(7) Steger, D. J.; Lefterova, M. I.; Ying, L.; Stonestrom, A. J.; Schupp, M.; Zhuo, D.; Vakoc, A. L.; Kim, J.-E.; Chen, J.; Lazar, M. A.; Blobel, G. A.; Vakoc, C. R. Dot1L/KMT4 Recruitment and H3K79 Methylation Are Ubiquitously Coupled with Gene Transcription in Mammalian Cells. Mol. Cell. Biol. 2008, 28, 2825-2839.

(8) Barski, A.; Cuddapah, S.; Cui, K.; Roh, T.-Y.; Schones, D. E.; Wang, Z.; Wei, G.; Chepelev, I.; Zhao, K. High-Resolution Profiling of Histone Methylations in the Human Genome. Cell 2007, 129, 823-837.

(9) Jo, S. Y.; Granowicz, E. M.; Maillard, I.; Thomas, D.; Hess, J. L. Requirement for Dot1L in Murine Postnatal Hematopoiesis and Leukemogenesis by MLL Translocation. Blood 2011, 117, 4759-4768.

(10) Feng, Y.; Yang, Y.; Ortega, M. M.; Copeland, J. N.; Zhang, M.; Jacob, J. B.; Fields, T. A.; Vivian, J. L.; Fields, P. E. Early Mammalian Erythropoiesis Requires the Dot1L Methyltransferase. Blood 2010, 116, 4483-4491.

(11) Bernt, K. M.; Zhu, N.; Sinha, A. U.; Vempati, S.; Faber, J.; Krivtsov, A. V.; Feng, Z.; Punt, N.; Daigle, A.; Bullinger, L.; Pollock, R. M.; Richon, V. M.; Kung, A. L.; Armstrong, S. A. MLL-Rearranged 
Leukemia Is Dependent on Aberrant H3K79 Methylation by Dot1L. Cancer Cell 2011, 20, 66-78.

(12) Slany, R. K. The Molecular Biology of Mixed Lineage Leukemia. Haematologica 2009, 94, 984-993.

(13) Daigle, S. R.; Olhava, E. J.; Therkelsen, C. A.; Majer, C. R.; Sneeringer, C. J.; Song, J.; Johnston, L. D.; Scott, M. P.; Smith, J. J.; Xiao, Y.; Jin, L.; Kuntz, K. W.; Chesworth, R.; Moyer, M. P.; Bernt, K. M.; Tseng, J. C.; Kung, A. L.; Armstrong, S. A.; Copeland, R. A.; Richon, V. M.; Pollock, R. M. Selective Killing of Mixed Lineage Leukemia Cells by a Potent Small-Molecule Dot1L Inhibitor. Cancer Cell 2011, 20, 53-65.

(14) Daigle, S. R.; Olhava, E. J.; Therkelsen, C. A.; Basavapathruni, A.; Jin, L.; Boriack-Sjodin, P. A.; Allain, C. J.; Klaus, C. R.; Raimondi, A.; Scott, M. P.; Waters, N. J.; Chesworth, R.; Moyer, M. P.; Copeland, R. A.; Richon, V. M.; Pollock, R. M. Potent Inhibition of Dot1L as Treatment of MLL-Fusion Leukemia. Blood 2013, 122, 1017-1025.

(15) Basavapathruni, A.; Olhava, E. J.; Daigle, S. R.; Therkelsen, C. A.; Jin, L.; Boriack-Sjodin, P. A.; Allain, C. J.; Klaus, C. R.; Raimondi, A.; Scott, M. P.; Dovletoglou, A.; Richon, V. M.; Pollock, R. M.; Copeland, R. A.; Moyer, M. P.; Chesworth, R.; Pearson, P. G.; Waters, N. J. Nonclinical Pharmacokinetics and Metabolism of EPZ-5676, a Novel Dot1L Histone Methyltransferase Inhibitor. Biopharm. Drug Dispos. 2014, 35, 237-252.

(16) Yu, W.; Chory, E. J.; Wernimont, A. K.; Tempel, W.; Scopton, A.; Federation, A.; Marineau, J. J.; Qi, J.; Barsyte-Lovejoy, D.; Yi, J.; Marcellus, R; Iacob, R. E.; Engen, J. R.; Griffin, C.; Aman, A.; Wienholds, E.; Li, F.; Pineda, J.; Estiu, G.; Shatseva, T.; Hajian, T.; AlAwar, R.; Dick, J. E.; Vedadi, M.; Brown, P. J.; Arrowsmith, C. H.; Bradner, J. E.; Schapira, M. Catalytic Site Remodelling of the DotlL Methyltransferase by Selective Inhibitors. Nat. Commun. 2012, 3, 12881298.

(17) Anglin, J. L.; Deng, L.; Yao, Y.; Cai, G.; Liu, Z.; Jiang, H.; Cheng, G.; Chen, P.; Dong, S.; Song, Y. Synthesis and Structure-Activity Relationship Investigation of Adenosine-Containing Inhibitors of Histone Methyltransferase Dot1L. J. Med. Chem. 2012, 55, 8066-8074.

(18) Yao, Y.; Chen, P.; Diao, J.; Cheng, G.; Deng, L.; Anglin, J. L.; Prasad, B. V. V; Song, Y. Selective Inhibitors of Histone Methyltransferase Dot1L: Design, Synthesis, and Crystallographic Studies. J. Am. Chem. Soc. 2011, 133, 16746-16749.

(19) Deng, L.; Zhang, L.; Yao, Y.; Wang, C.; Redell, M. S.; Dong, S.; Song, Y. Synthesis, Activity and Metabolic Stability of Non-Ribose Containing Inhibitors of Histone Methyltransferase Dot1L. MedChemComm 2013, 4, 822-826.

(20) Ibáňez, G.; McBean, J. L.; Astudillo, Y. M.; Luo, M. An EnzymeCoupled Ultrasensitive Luminescence Assay for Protein Methyltransferases. Anal. Biochem. 2010, 401, 203-210.

(21) A related protein-structural rearrangement of Dot1L is described in a Companion Paper: Scheufler, C.; Be, C.; Fernandez, C.; Moebitz, H.; Ragot, C.; Beyer, K.; Gaul, C.; Stauffer, F. Optimization of a Fragment-Based Screening Hit toward Potent DOT1L Inhibitors Interacting in an Induced Binding Pocket. ACS Med. Chem. Lett. 2016, 10.1021/acsmedchemlett.6b00167. Companion Paper.

(22) Anglin, J. L.; Song, Y. A. Medicinal Chemistry Perspective for Targeting Histone H3 Lysine-79 Methyltransferase Dot1L. J. Med. Chem. 2013, 56, 8972-8983.

(23) Scheufler, C. Personal communication.

(24) Bennett, B. D.; Kimball, E. H.; Gao, M.; Osterhout, R.; an Dien, S. J.; Rabinowitz, J. D. Absolute Metabolite Concentrations and Implied Enzyme Active Site Occupancy in Escherichia coli. Nat. Chem. Biol. 2009, 5, 593-599.

(25) The PyMOL Molecular Graphics System, version 1.5.0.4; Schrödinger, LLC. 